\title{
Una nueva comedia en colaboración entre ¿Calderón?, Rojas Zorrilla y Montalbán: Empezar a ser amigos a la luz del análisis estilométrico*
}

\author{
A New Play Written in Collaboration by \\ Calderón?, Rojas Zorrilla and Montalbán: A \\ Stylometric Analysis of Empezar a ser amigos
}

Claudia Demattè

Università di Trento ACEPTADO: 7 DE JUNIO DE 2019

Via Tommaso Gar, 14. Trento (Italia)

claudia.dematte@unitn.it

Orcid ID 0000-0002-9710-1689

Resumen: En la Tercera parte de comedias de Moreto se inserta una de dudosa atribución, Empezar a ser amigos, que vuelve a tratar un tema bastante difundido en el teatro del Siglo de Oro, la lealtad entre amigos frente a los celos motivados por el amor hacia una misma dama. La comedia se conserva también en una suelta atribuida a Juan Pérez de Montalbán y además en dos manuscritos y una edición impresa, todas estas atribuidas a Moreto. El estudio presenta una hipótesis de datación y trata de los problemas asociados a su atribución de autoría. Además de los instrumentos de filología e interpretación textual, se llevará a cabo un análisis estilométrico con el paquete Stylo que servirá de refuerzo para presentar una hipótesis de atribución para la que consideramos una comedia en colaboración posiblemente entre Calderón, Rojas Zorrilla y Montalbán.

Palabras clave: Juan Pérez de Montalbán. Calderón de la Barca. Francisco Rojas Zorrilla. Comedias en colaboración. Estilometría.
Abstract: A play of doubtful authorship is included in Agustín Moreto's Tercera parte de comedias: Empezar a ser amigos is a play about a common theme in Spanish Golden Age theatre, i.e. loyalty between friends that love the same woman. The play is conserved in a suelta whose author is Juan Pérez de Montalbán but also in two manuscripts and a print edition all ascribed to Moreto. The research presents an hypothesis of dating and debates the question of authorship. Together with the philological and critical instruments, we analyse the play with package Stylo in order to support with stylometry the thesis that Empezar a ser amigos is a play written in collaboration between Calderón, Rojas Zorrilla y Montalbán.

Keywords: Juan Pérez de Montalbán. Calderón de la Barca. Francisco Rojas Zorrilla. Plays Written in Collaboration. Stylometry.

\footnotetext{
* Esta investigación forma parte del PRIN Bando 2015 - "Il teatro spagnolo (1570-1700) e l'Europa: studio, edizioni di testi e nuovi strumenti digitali" y de las actividades del Grupo de investigación HÍLICA - Hibridismo literario y cultura áurea (ref. 970841 - UCM Santander).
} 
- mpezar a ser amigos es una pieza más bien mediocre, como afirma Victor - Dixon (1958,303), y es muy probable que nadie le hubiese dedicado aten— ción dentro del amplio panorama del teatro áureo de no ser por su presencia en la Tercera parte de las comedias de Agustín de Moreto. Contamos desde hace poco con una edición crítica que nace de la colaboración entre los grupos de los Moretianos y del proyecto dedicado a Juan Pérez de Montalbán, ya que en una rara suelta se había también atribuido a este último. ${ }^{1}$ Allí presenté por primera vez la hipótesis de que quizás se tratase de una comedia en colaboración entre tres ingenios: Francisco Rojas Zorrilla sería el autor del segundo acto y Montalbán el del tercero, mientras se deja sin atribución la del primero. Esta hipótesis llevaría a descartar la presencia de Moreto entre los colaboradores, debida sobre todo a la fecha de composición de la obra. La cuestión de la datación se ciñe a la primera referencia a la obra que Quiñones de Benavente insertó en su Loa de Rueda y Ascanio, obra que sabemos que fue estrenada en Madrid en ocasión de la Pascua de 1638. Pudo pues componerse algunos meses antes y posiblemente, según Restori (123), en fecha posterior al mes de junio de $1637 .^{2}$
LEÓN
Séanme todos testigos
que desde hoy sin extremos
don Orosio y yo queremos
Empezar a ser amigos.
MARÍA
Es ocasión oportuna
llegastes, como se ve:
favorecedme, o seré
el Monstruo de la fortuna. (Quiñones 594-95)

En la loa se mencionan un total de dieciocho títulos de comedias pero en ningún caso se nombra a los dramaturgos, dato que ha llevado a los críticos a distintas, y en algún caso erróneas, atribuciones. ${ }^{3}$ Si tuviéramos en cuenta a los

1 http://www.cervantesvirtual.com/obra/empezar-a-ser-amigos-940484/. De aquí en adelante las citas proceden de esta edición y se indican entre paréntesis en el texto. Remito a la edición para una detallada descripción de los testimonios (Empezar 7-11).

2 Restori (123) señaló primero la cita en la loa de Quiñones de Benavente y el dato fue sucesivamente recogido por Kennedy (147) y Dixon $(1958,303)$. La referencia al Mágico prodigioso de Calderón, compuesto para las fiestas del Santísimo Sacramento de 1637 según el manuscrito autógrafo, permite al estudioso italiano establecer la fecha post quem. Para el texto de la Loa ver Quiñones de Benavente 587-602 y Bergman 351-55.

3 Por ejemplo, Restori (121) no atribuye La más constante mujer a Montalbán, mientras que El monstruo de la fortuna se atribuye erróneamente a Rojas Zorrilla, Coello y Vélez de Guevara en la edición de la Loa de Arellano y otros (Quiñones de Benavente 599, v. 264n) a pesar de que ya 
autores más representados por número de obras en la Loa, encontraríamos a Montalbán ${ }^{4}$ y a Rojas Zorrilla con tres, ${ }^{5}$ mientras que Calderón figura con $\operatorname{dos}^{6}{ }^{6}$ a las que se añade una obra en colaboración entre los tres, El monstruo de la fortuna. ${ }^{7}$ Podemos además dejar constancia de que no hay ningún título de comedias de Moreto. ${ }^{8}$ La explicación puede que resulte obvia: si la datación es cierta, en el otoño de 1637 Moreto tendría menos de veinte años, todavía no había escrito nada para el teatro, aunque no tardaría en participar en la vida literaria madrileña. ${ }^{9}$ Curiosamente su primera incursión es un soneto que se publica en Las lágrimas panegíricas para la muerte de Montalbán (1639). ${ }^{10}$ Montalbán, por otra parte, muere en junio de 1638 con 37 años, ${ }^{11}$ pero sabemos que ya antes de la muerte de Lope había empezado a sufrir esa enfermedad que lo redujo al estado mental de un niño y a estar encerrado en un asilo de Madrid. ${ }^{12}$ Si realmente el discípulo de Lope participó en esta obra, debió de ser durante el verano de 1637.

Empezar a ser amigos es desde luego una obra poco estudiada, pero en varias ocasiones los especialistas de Montalbán y de Moreto han puesto en tela de juicio la atribución tanto a uno como a otro dramaturgo aunque sin llegar a datos concluyentes. ${ }^{13}$ Destaca en primer lugar la brevedad de cada uno de los tres actos (respectivamente 1054,982 y 879 versos), mientras que a nivel métrico hay que observar una limitada variedad de formas: se presentan tan

Mesoneros Romanos había incluido a Calderón y a Montalbán en la colaboración (Mesonero Romanos x).

4 La doncella labor, La más constante mujer y Los amantes de Teruel (respectivamente en Pérez de Montalbán 2014, 2016 y 2017).

5 Se trata de No hay amigo para amigo, Sin honra no bay amistad y Casarse por vengarse.

6 El Mágico prodigioso, cuyo manuscrito autógrafo permite a Restori (118) establecer la fecha post quem del auto, es decir, el SS. Sacramento de 1637; y Mejor está que estaba (citada erróneamente como Peor está que estaba).

7 Ver Volpe 2006 y González Cañal 2003.

8 En la edición de la Loa de Arellano y otros, la comedia Empezar a ser amigos se atribuye a Moreto sin más datos (Quiñones de Benavente 599, v. 254n).

9 Para las relaciones de Moreto y la ciudad de Madrid, ver Escribir entre amigos, 2018 y la bibliografía allí recogida.

10 Kennedy 23. Di Pastena subraya que Moreto fue uno de los autores ausentes en la Fama póstuma preparada por Montalbán para la muerte de Lope de Vega (Pérez de Montalbán 2001, LV).

11 Para la biografía de Montalbán ver Dixon 2013b, Pérez de Montalbán 2013, y http://www.cervantesvirtual.com/portales/montalban/.

12 La primera referencia a su enfermedad es del mismo dramaturgo en la Fama póstuma (Pérez de Montalbán 2001, 15). Ver además las palabras de Francisco de Quintana en el prólogo a las Lágrimas panegíricas $(1639,48)$. Para una reconstrucción de los últimos tres años de la vida de Montalbán, véase la Introducción al Segundo tomo de comedias (Pérez de Montalbán, vol. 2.1, 2019).

13 Para el repaso del juicio de estos críticos ver Empezar 1-4, Dixon 1958, 303 y Kennedy 148. 
solo tres tipos de agrupaciones, es decir, silva $(13,2 \%)$, redondilla $(32,9 \%)$ y romance que destaca con un $53,9 \%$ de presencia en la obra en su totalidad. En cada uno de los actos hay seis cambios métricos, pero en la primera jornada llama la atención el abundante uso de la redondilla que alcanza casi el mismo porcentaje del romance (respectivamente $43,46 \%$ y 45,54 ) mientras que se usa tan solo una vez y de forma limitada en la tercera $(15,47 \%)$. La variedad en la última jornada se alcanza gracias al uso de la silva en dos ocasiones $(20,70 \%)$, mientras que en las anteriores jornadas se presentaba tan solo una vez (respectivamente 10,8\% y 8,9\%). Volveremos sobre el uso de la silva más adelante, pero aquí resulta importante destacar que dentro de una misma paleta métrica y del mismo número de cambios, las jornadas presentan sin duda unos porcentajes métricos muy diferentes. En la edición (Empezar 11214) puse de relieve que al observar los hábitos métricos de otros dramaturgos que en estos mismos años tratan los mismos temas, es decir, en piezas de capa y espada dedicadas a la puesta en tela de juicio de la lealtad entre amigos frente al sentimiento amoroso, destaca que los usos de Rojas Zorrilla se corresponden al molde de nuestra comedia, mientras que se nota muy reducido con respecto a la polimetría impuesta por Lope de Vega. ${ }^{14}$ En particular la alta presencia de romance y redondillas que roza casi el $90 \%$ de los versos, se reconoce, según Pedraza (2007, 270), como un hábito métrico de Rojas, rasgo que confirma la atribución a este dramaturgo del segundo acto, pero también la presencia de su pluma en los otros dos: dentro de un proyecto de colaboración entre tres amigos, puede que a Rojas le haya tocado ejercer el papel de 'armonizador' del texto, visto el estado de salud de Montalbán. ${ }^{15}$ Como observa Roberta Alviti, "a uno de los poetas colaboradores se le encargaba leer el texto completo para enmendar incongruencias evidentes y garantizar cierta cohesión métrica y estilística" (25). Al ser una comedia de capa y espada, la composición de Empezar a ser amigos debió de ser diacrónica pues de esta for-

14 A pesar de los numerosos estudios sobre el dramaturgo, falta todavía un trabajo de conjunto de la métrica de Rojas, como subrayan Pedraza (Pedraza 2007, 269-76) y Vega García-Luengos (2000). Observamos que sigue todavía inédita la tesis de Doroty Duis mientras que el estudio de Mc Curdy en su edición de 1961 puede ser todavía punto de referencia (Rojas Zorrilla 1961, xviii, n. 7). Le agradezco a Germán Vega la referencia a un artículo de Azcune en que se da una versión actualizada del resumen de Mc Curdy presentando el análisis métrico de las ventitrés comedias de Rojas incluidas en las dos Partes de su teatro (Azcune 272-74).

15 Recordemos que en el prólogo a la Fama póstuma a la vida y muerte de Lope, escrito en el otoño de 1635, el mismo Montalbán admite sufrir de "un prolijo achaque que ha más de ocho meses que me tiene sin saludo y sin gusto" (Pérez de Montalbán 2001, 15). 
ma cada uno de los dramaturgos, después de haber compartido la ideación de la trama, podía jugar con la improvisación en su propio acto. En el corpus de las piezas colaboradas, destaca el hecho de que la comedia de capa y espada parece muy poco representada, pero esto no debe sorprender, según Alviti, "si se considera que este subgénero, basado en una serie de clichés y de mecanismos narrativos recurrentes, se caracteriza por la distinta combinación de los mismos elementos en cada pieza" (19) hasta el punto de que se relaciona más bien con el estro del dramaturgo más que con una trama preestablecida. Al mismo tiempo estoy de acuerdo con Germán Vega cuando afirma que si bien a cada uno de los dramaturgos le tocaba la composición de una parte, "se comprueba que no estaba blindada a la intervención de otros, y así la mano de Calderón puede apreciarse en parcelas diferentes a las de su encargo primordial" $(2017,201)$.

La colaboración entre Montalbán y Rojas no sería una novedad: alrededor de 1636, poco después de la muerte de Lope, los dos se hallaban sin duda alguna entre los dramaturgos más representados y la temprana muerte de Montalbán en 1638 lo excluyó de ese protagonismo que caracterizó a Rojas en el decenio sucesivo hasta su muerte en 1648. Los dos habían colaborado felizmente, si juzgamos por el éxito de esta pieza, con Calderón hacia 1632 en $\mathrm{El}$ monstruo de la fortuna (Pérez de Montalbán 2006), y durante largo tiempo sus nombres se encontraron vinculados a la controvertida atribución de Los privilegios de las mujeres. ${ }^{16}$ Hay que subrayar por otra parte que la primera colaboración de Calderón fue justamente con Montalbán y Mira de Amescua en el Polifemo y Circe hacia $1630 .{ }^{17}$ Calderón frecuentó las comedias de consuno algo más que su amigo Montalbán: ${ }^{18}$ serían trece hasta el momento, ${ }^{19}$ mientras que para Montalbán serían tres, dos con Calderón y una con Lope, Los terceros de san Francisco (Demattè 2017, 235-42). Una clara referencia de Quevedo en su polémica Perinola, a raíz de la publicación del Para todos (Plata 245-55), nos permite ahondar en el tema de las colaboraciones:

$¿$ Es uno que fue muchos años retacillo de Lope de Vega, que de cercenaduras de sus comedias se sustentaba, hasta que dio en escribir media

\footnotetext{
16 Acerca de Los privilegios de las mujeres, ver Vega García-Luengos 2007, 2009 y 2017, 191; Coenen 2009. Germán Vega apoya por una colaboración entre Rojas, Coello y Calderón. Estos tres colaboraron también en El jardín de Falerina (Pedraza 2017, 217-28).

17 Ver Demattè 2017, 232-33; González Cañal 2002, 545.

18 Para la amistad entre los dos, ver Dixon 2013a.

19 Recojo los datos de González Cañal (2002) y Vega García-Luengos (2017, 182).
} 
con limpio (poeta de la calle de los Negros) juntándose con otros para hacer pasos a escote? (Quevedo 1981, 176)

Amén de la muy conocida acusación de ser mero imitador del Fénix, no podemos descartar la idea de que a la altura de 1632, el éxito de las comedias en colaboración había marcado a Montalbán quien, por otra parte, en estos años recibe gran favor del público. ${ }^{20}$

La trayectoria de Rojas en las colaboradas fue algo más complejo, pues fue "sistemática y fervorosa" (Alviti y García González 95): entre las catorce ciertas del corpus escritas al alimón, cuatro veces colaboró con Calderón, cinco con Vélez de Guevara y seis con Antonio Coello, formando con estos dos un equipo bastante estable. ${ }^{21}$ La actividad de colaborador de Coello sería desde luego notable, según Montalbán, puesto que lo insertó en el Índice de los ingenios de Madrid de su Para todos (1633), como escritor de una Oración en octavas "de grande profundidad y valentía y [...] dos o tres comedias", pero subrayando su actividad de escritor de consuno, pues "sus pocos años desmienten sus muchos aciertos y de quien se puede decir con verdad que empieza por donde otros acaban" (Pérez de Montalbán 1999, 852). Fueron los estudios sistemáticos de Alviti los que nos demostraron claramente que hay una "tendencia de los comediógrafos, clara y acusada, de colaborar siempre con los mismos autores" (Alviti y García González 92). Pues no podemos dejar de observar que tanto Rojas como Montalbán habían colaborado con Mira de Amescua, pero este se había retirado a Guadix en 1631, quedando de esta forma excluido de la tríada que podría haber colaborado en 1637 para Empezar a ser amigos; Rojas y Calderón habían colaborado con Coello hacia 1636 con El jardín de Falerina y de hecho la colaboración entre Rojas y los hermanos Coello es muy estrecha en los años 1636-1637..$^{22}$ Como subraya González Cañal, Rojas Zorrilla colabora en cinco ocasiones con Calderón y Coello, mientras que Rojas colabora con Montalbán en tres ocasiones (González Cañal 2002, 545). A la luz de estos datos del ambiente teatral alrededor de la fecha

20 Recuérdese las palabras del Marqués de Careaga en "La poesía defendida, y definida, Montalbán alabado", en las Lágrimas panegíricas (1639) quien menciona que la comedia No bay vida como la honra "en ambos patios, o Teatros desta gran Corte, a una misma hora, por muchos días se representó por dos autores: cosa que jamás se ha visto, ni dicho de ninguno, aunque entre en ellos el Fenis deste arte, y el Fenis de su amistad, Lope" (17v-18r). Ver Demattè y Del Río (8081 y 90$)$.

21 Para el corpus, véase Alviti y García González (95-96).

22 González Cañal 2017, 113-26 y García González 2017, 93-102. 
de composición de nuestra comedia y pensando en un colaborador habitual, se podría pues restringir la autoría del primer acto a Calderón y a Antonio Coello. Por lo que atañe a Antonio Coello, González Cañal observa que este dramaturgo utiliza la quintilla en casi todas sus obras ${ }^{23}$ y en el caso de Empezar a ser amigos observamos la ausencia total de quintillas que apuntaría a descartar a Coello como colaborador. No es nada más que un dato y una intuición, ya que los estudios sobre el estilo de Antonio Coello y las obras a nuestro alcance todavía no nos permiten ahondar en este análisis. Pasemos al segundo nombre que barajamos, el de Calderón. Las doce obras que le vieron como colaborador son casi todas anteriores a 1644 , para subrayar no solo la época de mayor auge de las comedias de consuno en la década de los treinta sino también para marcar que fue una actividad prevalentemente temprana en la producción teatral de Calderón ${ }^{24}$ y que nunca estimó mucho esta actividad en colaboración ya que las excluyó, por ejemplo, de la lista de sus casi cien obras en 1680 (González Cañal 2002, 551). Si es cierto que la materia de las obras en colaboración aprovechaba de temas ya conocidos, como bien detalla González Cañal, "parece que Calderón aprovechó de estas comedias en colaboración, a modo de ensayo, para componer más tarde en solitario nuevas obras sobre los mismos asuntos, más cuidadosas y depuradas" (González Cañal 2002, 551-52). Germán Vega, al analizar los calcos parciales o totales que se presentan en esta última pieza, trata de los usufructos de la colaboración en Los privilegios de las mujeres en su obra individual Las armas de la hermosura, compuesta bastantes años después. Si es cierto que tan solo en raros casos se pueden demostrar la relaciones directas y textuales entre las dos piezas, "en las demás, solo debieron de influir a través del recuerdo que guardaba de ella" (Vega García-Luengos 2017, 201). En mi opinión es el caso de la relación entre Empezar a ser amigos y la comedia calderoniana No siempre lo peor es cierto, cuya datación se sitúa entre 1640-1642. No hay prueba textual evidente de calcos, salvo un detalle lingüístico que me llevó a descubrir esta comedia que comparte con Empezar a ser amigos el enredo y los nombres de los protagonistas. En el v. 115 de Empezar a ser amigos aparece "ir en cas" con el significado de "ir a casa"; la expresión se repite en el v. 158, "de en cas de mi dama". Esta expresión, corriente en época medieval y todavía registrada en textos del

23 El estudioso utiliza este dato para confirmar la adscripción de la tercera jornada de El robo de las Sabinas $(2017,119)$.

24 González Cañal 2002, 545. A excepción de dos que se publicaron en los años cincuenta. 
Siglo de Oro de varios autores, ${ }^{25}$ la encontramos también en algunas comedias de Calderón: por ejemplo, hay tres recurrencias en No hay cosa como callar; cuatro en Dar tiempo al tiempo y hasta cinco en No siempre lo peor es cierto. ${ }^{26} \mathrm{En}$ esta última pieza destaca la presencia de Violante ("a no ir en cas de Violante a un recado"), nombre que coincide con la dama de Empezar a ser amigos, y aún llama más la atención si consideramos que coinciden los nombres de los principales protagonistas de las dos piezas: don Carlos, doña Leonor y doña Violante..$^{27}$ A este propósito Victor Dixon, en su hipótesis de atribución de El sufrimiento premiado a Lope, afirma que "en cuestiones de atribución, los nombres mismos de los personajes de una comedia no dejan de tener su importancia, puesto que cada autor había de tener su propio criterio de selección" (1967, xix). Al haber empezado con el primer acto, bien podría haber elegido Calderón los nombres de los protagonistas y elegiría volver a utilizarlos (a pesar de que admito que son nombres comunes, 'de comedia') en $N_{0}$ siempre lo peor es cierto. ${ }^{28}$ Asimismo, también el desenlace de estas comedias de capa y espada tienen bastantes hechos paralelos con Empezar a ser amigos. Recuerdo solo, por no ser una de las piezas más conocidas de Calderón, los elementos que comparten ya a partir de la primera escena: en Madrid don Carlos, al entrar a la habitación de Leonor para un encuentro nocturno, encuentra a un embozado y después de una riña lo deja casi muerto y, contra su

25 Hay que observar que aunque haya desaparecido de la norma culta, pervive en otros niveles sociolingüísticos (Choi 186-88).

26 En la base de datos ARTELOPE "en cas de" resulta presente en una treintena de obras (www.artelope.uv.es) mientras que el repertorio del Teatro Español del Siglo de Oro (TESO) nos brinda unos cien usos, entre los cuales anotamos la presencia de quince obras de Calderón; en la mayoría de ellas "ir en cas de" se presenta tan solo una vez. Por supuesto, y para utilizar las palabras de Marcella Trambaioli, "la mera presencia de dicha palabra en el entramado poético de la comedia no constituye ninguna prueba de una efectiva intervención de este autor en la escritura de la pieza" (192).

27 En el Diccionario de personajes de Calderón se señalan cinco piezas en las que aparece el personaje de Violante, mientras no aparece mencionada su presencia en No siempre lo peor es cierto, puesto que Violante solo se nombra y nunca sale a la escena. Nótese además que en dos de las cinco piezas coincide por lo menos otro nombre de personaje: en Cada uno para sí el galán de Violante se llama don Carlos mientras la otra dama protagonista se llama Leonor; en También bay duelo en las damas, Violante es la dama enamorada de don Félix y amiga incondicional de su hermana Leonor" (Diccionario de personajes de Calderón 2002, 487).

28 Publicada en la Octava parte de comedias (1684) de Calderón, la pieza No siempre lo peor es cierto no ha merecido la atención de la crítica hasta el momento. Utilizo la reproducción digital de esta parte conservada en la Biblioteca Nacional de España (Sig. T/1847, 156-200, disponible online). A pesar de que Hilborn $(1935,97)$ la situase hacia 1648-1650, según Ann L. MacKenzie "a more probable date, however, would appear to be 1640-1642" por las afinidades con El pintor de su deshonra (Calderón 139). 
voluntad, puesto que cree que Leonor lo traiciona, tiene que raptarla de la casa paterna ya que su honor está perjudicado. Don Carlos la lleva a Valencia y pide ayuda a su primo don Juan quien le propone que Leonor se quede en su casa fingiendo ser una criada, ya que don Carlos quiere alistarse para perder de vista a Leonor, a quien ama y aborrece al mismo tiempo. El agraviador es en realidad el galán de la hermana de don Juan, Beatriz, quien descubre que él ha estado en Madrid galanteando a otra mujer y se siente ofendida. Ya a estas alturas entendemos que el agraviador, don Diego, ha ofendido a dos mujeres y ha penetrado en dos casas en dos ciudades diferentes, así que tiene dos enemigos, es decir, don Carlos y también don Juan por ser primo y también hermano ofendido. La situación se complica cuando don Juan pide a don Carlos que se quede en un escondite en su cuarto, que representaría la puerta que comunica con la otra casa en Empezar a ser amigos, medio que permite al personaje ver y escuchar sin ser visto. Cuando don Diego vuelve a visitar a Beatriz y por temor a ser descubierto se esconde en una habitación donde se encuentra Leonor. Don Carlos y todos los otros piensan que ha vuelto de Madrid siguiendo a Leonor. Además llega a Valencia el padre de Leonor con una carta del Marqués de Denia, protector de don Juan, para este que ayude al padre a encontrar a su hija y a vengar su ofensa. Al pobre don Juan, exactamente como pasaba a don Carlos en Empezar a ser amigos, le toca pues ejercer de primo, amigo, hermano, protector y servidor de cada uno de los personajes, sin saber cómo hacerlo sin agraviar a los otros. Si bien al principio los dos primos piensan que lo mejor es forzar a don Diego a casarse con Leonor, en un segundo momento descubren que Leonor es inocente y que es don Diego quien le ha ofendido sin que ella nunca haya respondido a su amor. El final puede parecer feliz, puesto que don Carlos se casa con Leonor y Beatriz con don Diego, sin embargo como en Empezar a ser amigos, es bastante amargo pues no hay que olvidar que don Diego en cuanto pudo traicionó a Beatriz en Madrid y también en Valencia al mentirle en su primer encuentro al respecto de ese episodio. Si la Violante de Empezar a ser amigos acaba casándose con el asesino de su hermano, la Beatriz de No siempre lo peor es cierto lo hace con un mujeriego mentiroso. ${ }^{29}$

El análisis del estilo de los autores se ha llevado a cabo hasta el momento de forma filológicamente tradicional, pero querría ahora proponer un acer-

29 Observamos que No siempre lo peor es cierto aparece, como veremos, entre las veinte obras más cercanas en el análisis estilométrico del primer acto (ver fig. 3 infra). 
camiento distinto para apoyar con ulteriores datos mi hipótesis de atribución de los tres actos. La estilometría es una herramienta digital que desde hace algunos años se ha aplicado también a la literatura española (ver Fradejas, Rojas Castro y Calvo Tello 2016 y 2018). A pesar de que llevaba años interesándome por el tema, hasta que no aprendí personalmente a utilizar estas herramientas, no caí en qué medida la estilometría podía apoyar las investigaciones de los filólogos. Estoy pensando principalmente en el paquete Stylo, una aplicación escrita en el lenguaje R (Eder, Rybicki y Kestemont 2016 y 2017) para la estilística computacional o análisis estilométrico. Es relativamente simple de usar ya que a través de una interfaz gráfica (GUI) permite llevar a cabo distintos tipos de análisis dentro de los cuales los que utilizamos para este estudio son tan solo una mínima parte. El punto de partida que posibilita el análisis es un corpus de extensión considerable como para cubrir tanto la variedad de autores como de estilo de todos y cada uno de los dramaturgos. Por esta razón empezó mi colaboración con Germán Vega, quien está preparando un corpus del teatro del Siglo de Oro gracias a la aportación de los distintos proyectos de los dramaturgos principales y al rastreo del corpus que ya está en línea. ${ }^{30}$ En el momento en se escribió este trabajo, el corpus contaba con 561 obras del teatro español del siglo XVII. Al contrario de lo que ocurre con el conjunto de textos que atañe a estudios sobre literatura contemporánea que rastrean principalmente la web para encontrar sus textos, el problema es que solo gracias al trabajo de equipo de distintos grupos de investigación y compartiendo nuestros datos podremos manejar un corpus teatral lo suficientemente amplio como para encontrar la solución a los numerosos problemas de atribución y confirmación de nuestras hipótesis. Montalbán entró en el corpus con una quincena de obras que consideramos ciertas: las doce de su Primer tomo de comedias (1635), cuya publicación cuidó el mismo Montalbán, y tres comedias sueltas (Morir y disimular, Gravedad en Villaverde y La más constante mujer). ${ }^{31}$ Además insertamos dos comedias del Segundo tomo que se publicó póstumo, en 1638, bajo el cuidado del padre de Montalbán, el famoso librero Alonso Pérez (Cayuela 2005): una comedia cierta, Don Florisel de Niquea, ${ }^{32}$ y una que ha planteado problemas de atribución, El sufrimiento premia-

$30 \mathrm{El}$ proyecto principalmente se vale de la ayuda de Álvaro Cuellar (http://estilometriatso.com/).

31 Las tres comedias están editadas en Pérez de Montalbán 2016. Sobre la publicación del Primer tomo, ver Pérez de Montalbán 2013, 1-9.

32 Para el estudio y el texto de esta comedia, ver Demattè y Del Río. 
do, que Dixon (1967) atribuyó a Lope. Esta última elección ha sido barajada para poner a prueba la herramienta, como veremos.

Dentro del corpus de referencia, una de las opciones que ofrece Stylo es calcular la proximidad entre las obras por la frecuencia de sus palabras. Se han tomado en consideración las mil palabras más frecuentes aunque sabemos que tampoco varía demasiado con otras opciones, por ejemplo cien palabras. En el primer dendograma (fig. 1) se puede observar cómo de manera natural los textos del corpus se unen en grupos uniformes de obras de un mismo autor:

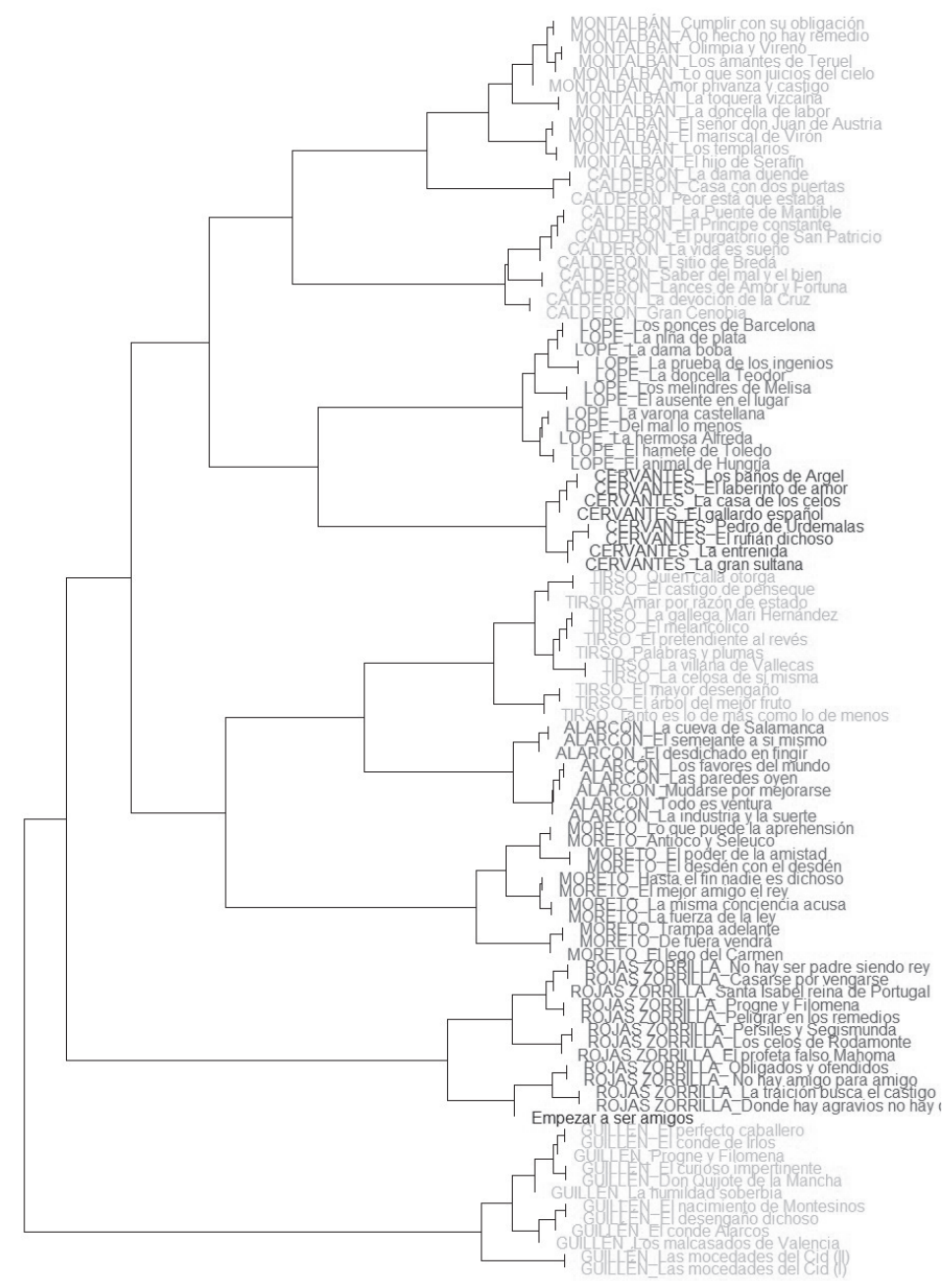

Fig. 1 Dendograma general del corpus analizado del teatro del Siglo de Oro. 
Las 561 obras se sitúan correctamente en el dendograma reconstruyendo los grupos de comedias que pertenecen a cada uno de los dramaturgos. En detalle (fig. 2) podemos apreciar que todas las obras de Montalbán a excepción de una se colocan juntas. La que se aleja del grupo es El sufrimiento premiado que se sitúa en el medio de la producción de Lope de Vega. Esta comedia se introdujo deliberadamente en el corpus para representar un elemento conflictivo y el análisis estilométrico confirmó la atribución de Dixon.

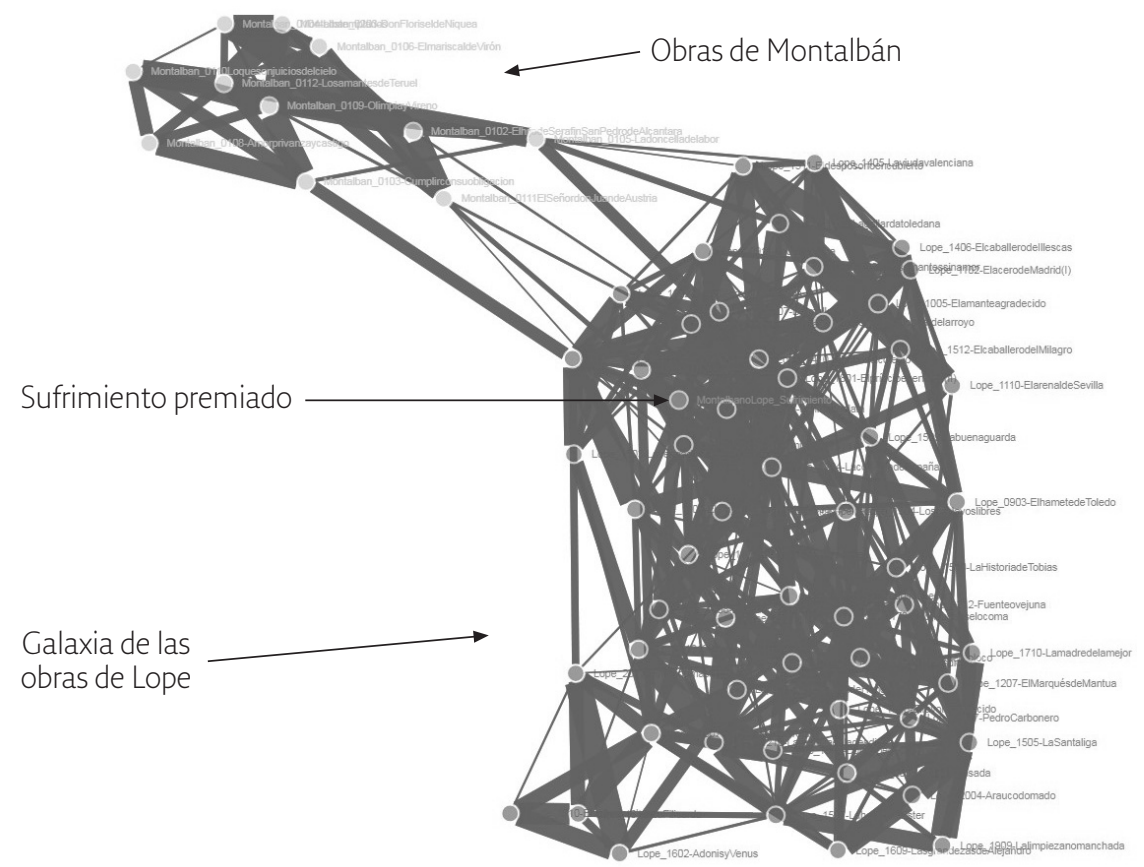

Fig. 2. Red de las comedias de Lope y de Montalbán con El sufrimiento premiado.

Considerando las mil palabras más frecuentes, podemos además, a través del paquete Stylo, mostrar cuáles son las veinte obras más cercanas a la comedia objeto de estudio. Utilizamos como botón de muestra una comedia cierta de Montalbán, Los amantes de Teruel (fig. 3). ${ }^{33}$

33 La elección de la obra sirve para confirmar los resultados de la herramienta Stylo y por eso se eligió una de las comedias más famosas de Montalbán cuya atribución nunca se ha puesto en duda, como confirma el estudio de Teresa Ferrer (Pérez de Montalbán 2017). 


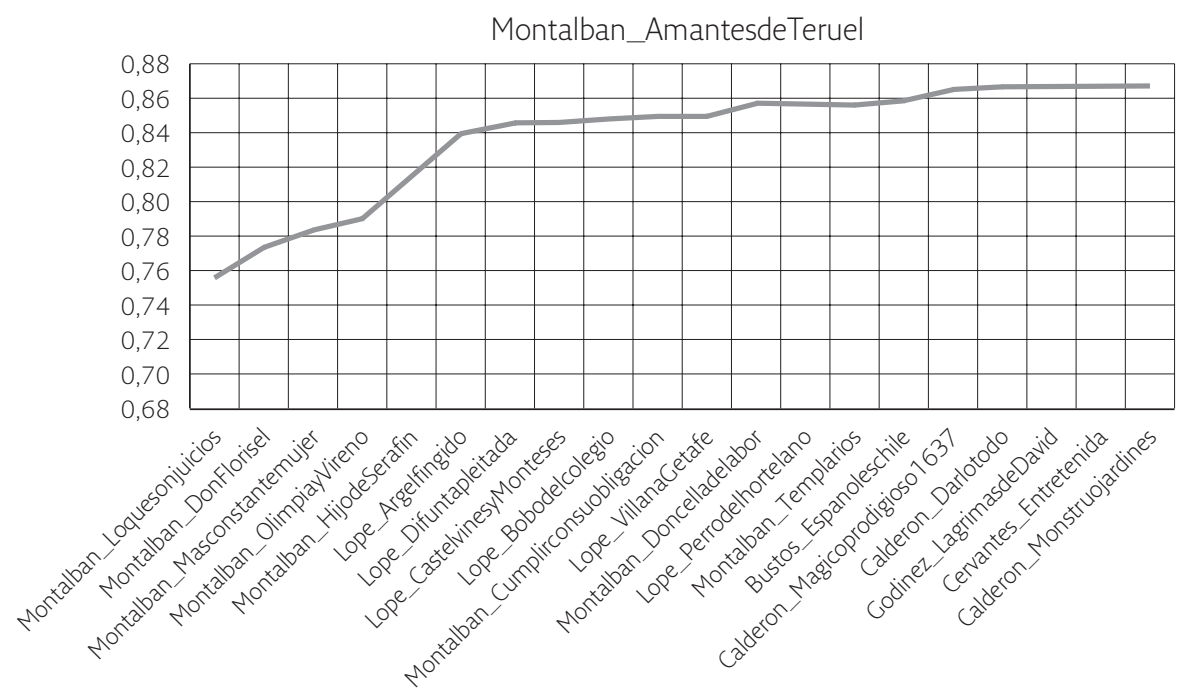

Fig. 3. Gráfico de las 20 obras más cercanas a Los amantes de Teruel.

El resultado nos muestra que aparecen doce obras de Montalbán seguidas por seis de Lope y destaca que las primeras cinco son de Montalbán, es decir que se ajusta bien al estilo de Montalbán.

Apliquemos el mismo acercamiento con las mil palabras más frecuentes a la pieza Empezar a ser amigos (fig. 4).

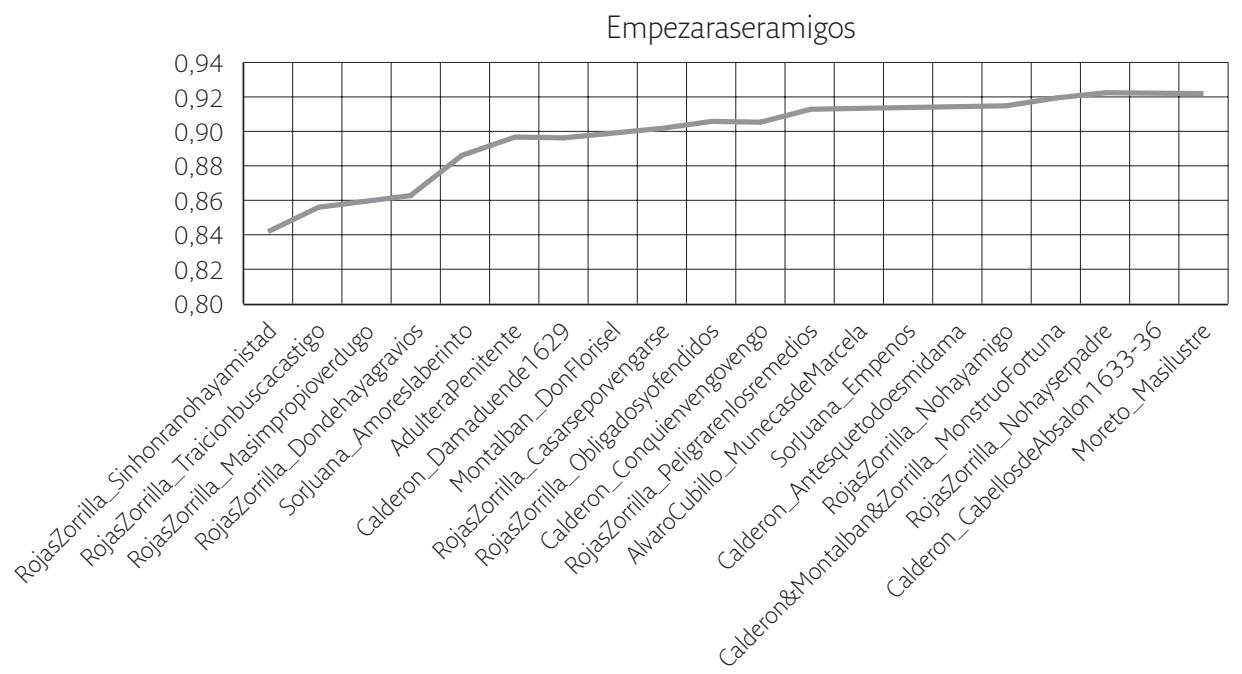

Fig. 4. Gráfico de las 20 obras más cercanas a Empezar a ser amigos. 
El resultado es muy diferente ya que entre las 20 obras más cercanas se encuentran nueve obras de Rojas Zorrilla, cuatro de Calderón y tan solo una comedia de Montalbán, Don Florisel de Niquea, y una en colaboración entre Rojas, Montalbán y Calderón, El monstruo de la fortuna..$^{34}$ A primera vista parecía una reunión de dramaturgos diferentes y eso apoyó la tesis de que podría tratarse de una comedia en colaboración. Analizamos, pues, cada una de las jornadas de Empezar a ser amigos por separado utilizando los mismos parámetros de acercamiento.

Empezaraseramigos( ()

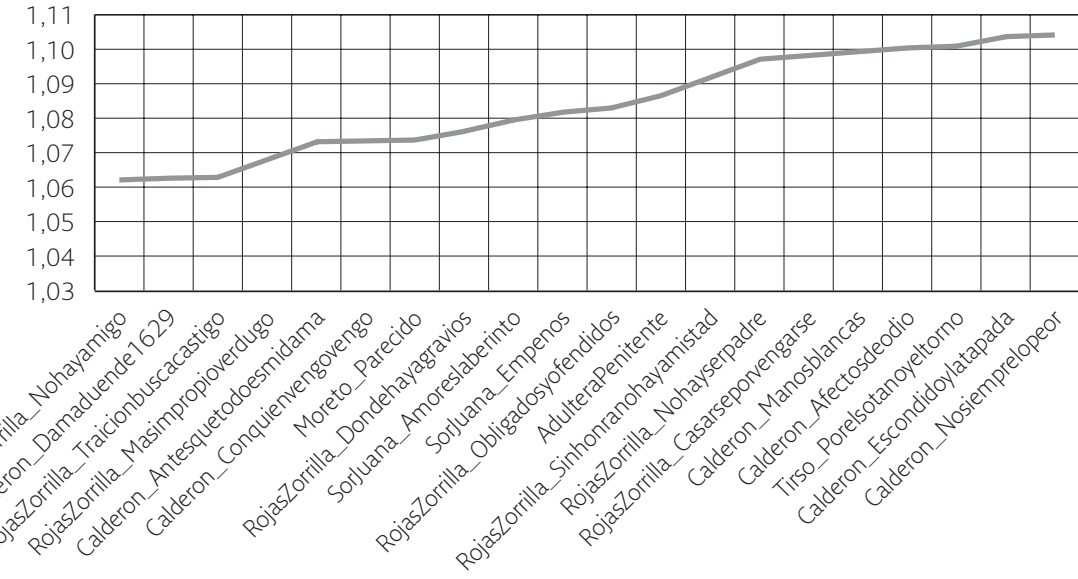

Fig. 5. Empezar a ser amigos: I acto

Por lo que atañe al primer acto (fig. 5), observamos que aparecen ocho comedias de Rojas, de las cuales tres situadas en las primeras seis; siete de Calderón, tres en las primeras seis (entre ellas destaca No siempre lo peor es cierto); pero ninguna comedia de Montalbán:

34 El objetivo de este trabajo no permite disponer del espacio suficiente para analizar cada una de las veinte obras más cercanas. Nótese además que la producción dramática de sor Juana es posterior a la muerte de Montalbán y que la comedia en colaboración La adúltera penitente es posiblemente de 1652 (La adúltera penitente, 2). Por lo que atañe a las comedias en colaboración, se han insertado en el corpus tanto la obra en su conjunto como cada uno de los actos atribuidos a sus respectivos autores, a sabiendas de que cuanto más corto es el texto menos resultados fiables ofrece el análisis. En el caso de La adúltera penitente el resultado de cada uno de sus actos sale de las treinta obras más cercanas mientras que la obra en su conjunto se sitúa entre las primeras diez. Todavía falta un análisis estilométrico que abarque las obras en colaboración aunque me consta que Álvaro Cuellar está trabajando actualmente en estos temas. 


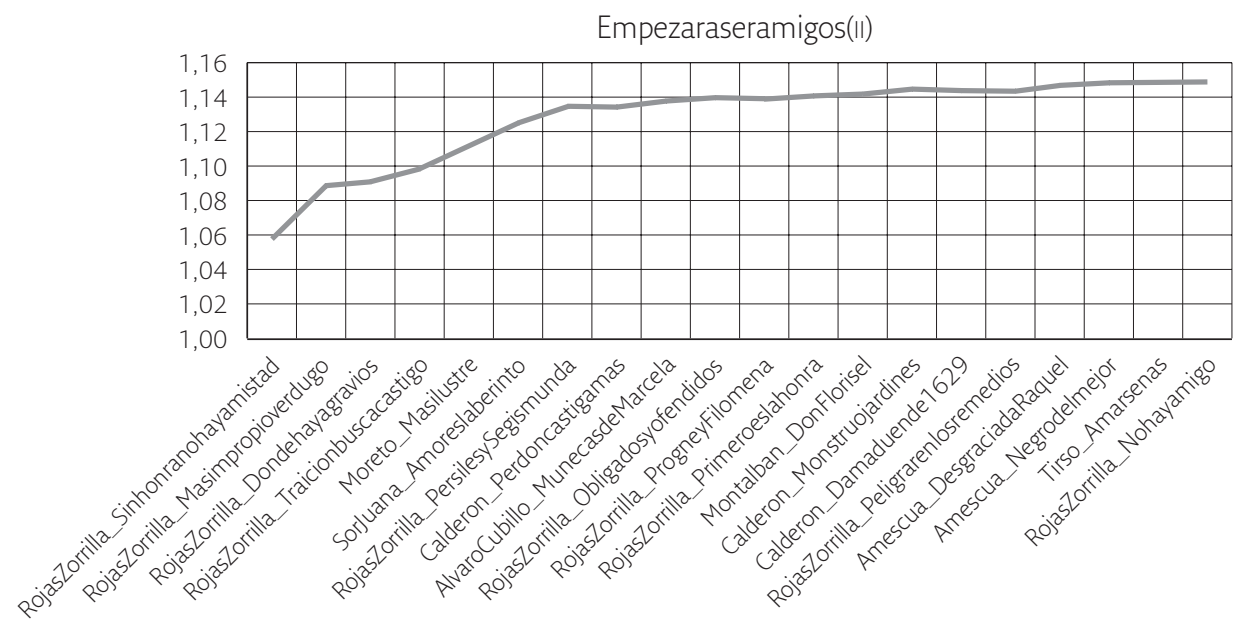

Fig. 6. Empezar a ser amigos: II acto

En el segundo acto (fig. 6), aparecen diez comedias de Rojas y llama la atención que las cuatro primeras son suyas; tres de Calderón y una de Montalbán, Don Florisel de Niquea. Si comparamos estos resultados con los de Los amantes de Teruel para la autoría de Montalbán, todo apunta al hecho de que sea Rojas el autor de este segundo acto.

Empezaraseramigos(III)

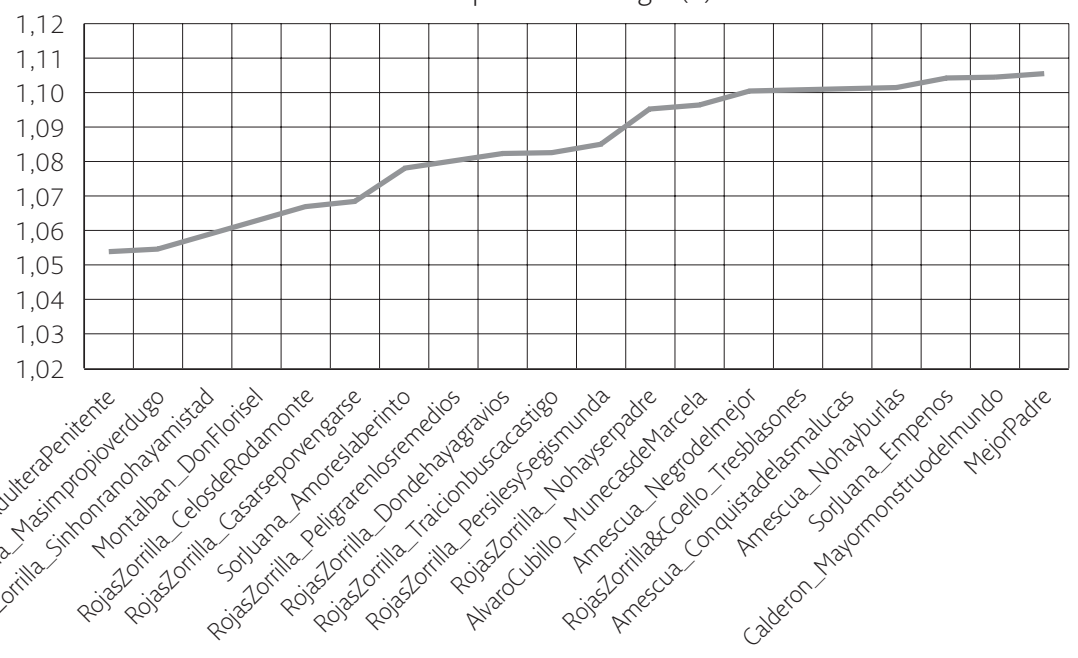

Fig. 7. Empezar a ser amigos: III acto 
En el tercer acto (fig. 7), destacan diez comedias de Rojas, nueve en las primeras doce comedias; la cuarta comedia es el Don Florisel de Montalbán; Calderón casi no está presente (una comedia, casi última); por lo que atañe a la presencia de La adúltera penitente, comedia en colaboración entre Cáncer, Moreto y Matos Fragoso, hay que considerar que fue compuesta posiblemente en $1652 . .^{35}$

Si ya en la edición de Empezar a ser amigos (18-24), la atribución de la segunda jornada a Rojas Zorrilla se daba por cierta, ahora las herramientas informáticas lo confirman. Al mismo tiempo nos señalan que la pluma de Rojas está presente tanto en la primera como en la tercera jornada, dato que confirma la hipótesis de que las comedias en colaboración contaban con un "armonizador", Rojas Zorrilla, que revisaba el trabajo en su conjunto. El análisis estilométrico de la tercera jornada confirma la presencia, aunque débil, de rasgos estilísticos y métricos de la última etapa de Montalbán en la cual se inserta el Don Florisel de Niquea. ${ }^{36}$ Se pueden observar, a nivel textual, el frecuente uso de la metáfora del arroyo (Empezar, v. 2525; Profeti 1970, 162-63), la esticomitia doble (Empezar, vv. 2775-84), las repeticiones (Don Florisel 1971-77; Empezar, vv. 2510-13) y la imagen de Troya abrasada (Don Florisel, vv. 2170-88; Empe$z a r, \mathrm{v} .2188)$. La atribución del tercer acto no resulta tan inmediata, sobre todo si nos referimos a la presencia de la silva, una presencia que es muy irregular en cada uno de los actos: un $10,8 \%$ en el primero, un $8,9 \%$ en el segundo y un $20,7 \%$ en el tercer acto. Williamsen sugiere en su estudio que la irregularidad propia de la silva realzaba en las situaciones claves la percepción de las palabras que riman $(1978,884-85)$ y un análisis de los momentos en que se utiliza nos confirma este uso (Empezar, vv. 477-590, 1327-414, 2223-342 y 2694-755). Las preferencias métricas de Montalbán, según Parker (199) apuntan hacia un mayor porcentaje de silvas en el segundo periodo de su producción, años en que escribe también el Don Florisel de Niquea que presenta un $15,8 \%$ de silva, ${ }^{37}$ pero sobre todo el estudioso marca un alto porcentaje de silva en las comedias en colaboración: el Polifemo y Circe presenta un 23,4\% y en Los privilegios de las

35 Ver Álvarez Sellers y La adúltera penitente.

36 Ver Demattè y Del Río.

37 En la comedia Don Florisel destaca el alto porcentaje de silvas en el segundo acto con un 24,04\%, mientras los porcentajes del primero $(14,01 \%)$ y del tercero $(9,62 \%)$ resultan los usuales en Montalbán. Con respeto al porcentaje total de silvas (16,7\%) indicado por Parker $(1952,187)$, en su momento había matizado los datos aunque había indicado tan solo "pareados" allá donde habría sido más correcto indicar "silva de pareados" (Demattè y Del Río 2012, 152-53). 
mujeres el 26,4\% (Parker 207). ${ }^{38}$ En estas dos comedias, como aclaró Germán Vega (2007), la intervención de Montalbán se limitó a la primera mientras que Calderón participó en las dos. Hay que tener en cuenta, además, que Marín subrayó en su análisis que la silva es la única forma métrica italianizante siempre presente en las dieciocho comedias de Calderón que tomó en consideración (356-57) y que Hilborn aclaró en su momento cómo la silva se utilizaba principalmente en Calderón en pasajes "preparatory to high points of actions" $(1943,148)$, datos que nos llevan a pensar que podría ser una elección métrica de Calderón en el primer acto que los demás autores adoptaron..$^{39}$ La práctica de la escritura de consuno, pues, parece que en Empezar a ser amigos confirme esas tendencias subrayadas por Germán Vega en el caso de Los privilegios de las mujeres, es decir, "la flexibilidad de las intervenciones de los diferentes colaboradores, que pueden o no limitarse a las fronteras de cada acto" $(2009,487)$ y el aprovechamiento de expresiones e imágenes de cada uno de los colaboradores, que explica cómo la actividad de circunstancia de este escritura hacía que se le atribuyese menos atención y responsabilidad que en la composición individual. Si volvemos al primer acto, queda claro que los datos para poder atribuirlo a Calderón resultan todavía débiles: los instrumentos de la estilometría en este caso nos ayudan a no descartar esa hipótesis pero solo un análisis pormenorizado de los calcos y estilemas presentes en el primer acto con respeto a la producción dramática de Calderón en la tercera y cuarta décadas del s. XVII, nos ayudará a confirmar eventualmente la atribución, "sin perder de vista en ningún momento que el lenguaje poético de las obras colectivas tiende a un inevitable sincretismo" (Trambaioli 203). ${ }^{40}$

La última palabra está en manos de los filólogos porque para establecer el corpus, los criterios de análisis e interpretar los datos hace falta apoyar críticamente, como siempre hemos hecho, todas y cada una de las suposiciones, para llegar a confirmar que las herramientas informáticas pueden ayudarnos en nuestro trabajo ecdótico. La amplitud del corpus con el que trabajamos es el elemento quizás más importante de todo acercamiento, pero en el caso de

38 Sobre la silva, ver Asensio 1983, 29.

39 Observamos que el uso de la silva en Rojas Zorrilla no es nunca alto a no ser en las comedias en colaboración con los hermanos Coello (con porcentaje 36\%, González Cañal 2017, 119-20). Por otra parte falta un estudio de conjunto sobre la utilización de la silva en las comedias de Montalbán con atención a las distintas jornadas y escenas en la línea de los estudios de Leonor Fernández Guillermo (2008).

40 Ver también Coenen para el tema de la atribución a Calderón de actos de comedias en colaboración. 
las atribuciones, sin una sospecha evidente difícilmente encontramos al autor de un texto anónimo, tanto antiguo como contemporáneo. ${ }^{41}$ Esa sospecha significa que el corpus tiene que contener una muestra representativa del posible autor y por eso es necesario proceder a la edición de los textos de autores que hasta hoy no han merecido la atención de la crítica.

La filología tradicional y las modernas herramientas se han utilizado conjuntamente en este caso para descartar en primer lugar la atribución de la obra completa tanto a Moreto como a Montalbán y a seguir las sendas de las comedias en colaboración. En mi opinión los datos aportados pueden con suficiente fuerza apoyar que Empezar a ser amigos es, en primer lugar, una comedia de consuno; en segundo lugar, que se podría tratar de una colaboración entre Calderón o un autor de su escuela (I), Rojas Zorrilla (II) y Montalbán (III), en donde la mano de Rojas Zorrilla como aglutinador puede apreciarse en las diferentes jornadas de la pieza. Según Déodat-Kessedjian, en referencia a $E l$ monstruo de la fortuna, "la colaboración entre Calderón, Montalbán y Rojas Zorrilla va más allá de unos simples recuerdos textuales de una jornada a otra. Un verdadero proceso de escritura en común aparece y crea una verdadera unidad en el modo de componer un drama" (Déodat-Kessedjian 224). Pues si esta era la forma de colaborar entre ellos, "hacer pasos a escote" (Quevedo 1981, 176) con dos amigos no sería una mala actividad para los últimos meses de vida de Montalbán.

\section{OBRAS CITADAS}

Álvarez Sellers, María Rosa. "Comedias en colaboración entre Moreto, Cáncer y Matos Fragoso: La adúltera penitente y ¿La fuerza del natural?”. Serenísima palabra. Eds. Anna Bognolo y otros. Venezia: Edizioni Ca' Foscari, 2017. 363-74.

Alviti, Roberta. "El proceso de escritura en colaboración: sincronía y diacronía". La comedia escrita en colaboración en el teatro del Siglo de Oro. Ed. Juan Matas Caballero. Valladolid: Universidad de Valladolid, 2017. 15-27.

Alviti, Roberta, y Almudena García González. "Obras en colaboración”. El universo dramático de Rojas Zorrilla. Ed. Rafael González Cañal. Valladolid: Ediciones de la Universidad de Valladolid, 2015. 91-105.

$41 \mathrm{El}$ caso del descubrimiento, gracias a la estilometría, de la autoría de la novela The Cuckoo's Calling publicada por J. K. Rowling bajo el pseudónimo de Robert Galbraith es sin duda el que más eco tuvo en la prensa internacional en 2013. 
Asensio, Eugenio. "Un Quevedo incógnito: las silvas". Edad de oro 2 (1983): $13-43$.

Azcune, Valentín. "Miscelánea erudita". Cuadernos de Investigación de la literatura bispánica 25 (2000): 267-80.

Bergman, Hannah E. Luis Quiñones de Benavente y sus entremeses. Madrid: Castalia, 1965.

Calderón de la Barca, Pedro. Four Comedies. Ed. L. Ann MacKenzie. Trad. Kenneth Muir. Lexington: University Press of Kentucky, 1980.

Calvo Tello, José. "Entendiendo Delta desde las Humanidades". Caracteres 5.1 (2016): 140-76.

Calvo Tello, José, y Juan Cerezo Soler. "La conquista de ferusalén ¿̇de Cervantes? Análisis estilométrico sobre autoría en el teatro del Siglo de Oro español”. Digital Humanities Quarterly 12.1 (2018).

Cayuela, Anne. Alonso Pérez de Montalbán. Un librero en el Madrid de los Austrias. Madrid: Calambur, 2005.

Choi, Jinny K. "The genesis of voy en el mercado: The preposition en with directional verbs in Paraguayan Spanish". Word 52.2 (2001): 181-96.

Coenen, Erik. "Las atribuciones de Vera Tassis". Castilla. Estudios de Literatura 0 (2009): 111-33.

Demattè, Claudia, y Alberto del Río. Parodia de la materia caballeresca y teatro áureo. Edición de Las aventuras de Grecia y su modelo serio, el Don Florisel de Niquea de Montalbán. Pamplona: Universidad de Navarra, 2012.

Demattè, Claudia. "La fortuna de las obras de Montalbán entre reescrituras, parodias y traducciones: el caso de la comedia No hay vida como la honra". Il prisma di Proteo. Riscritture, ricodificazioni, traduzioni fra Italia e Spagna (sec. XVI-XVIII). Ed. Valentina Nider. Trento: Università degli Studi di Trento, 2012. 79-98.

Demattè, Claudia. "Entre ingenios anda el juego: Juan Pérez de Montalbán y las comedias en colaboración con Lope y Calderón”. La comedia escrita en colaboración en el teatro del Siglo de Oro. Ed. Juan Matas Caballero. Valladolid: Universidad de Valladolid, 2017. 229-42.

Déodat-Kessedjian, Marie-Françoise. "Las obras escritas en colaboración por Rojas Zorrilla y Calderón”. Francisco de Rojas Zorrilla, poeta dramático. Eds. Felipe B. Pedraza, Rafael González Cañal y Elena Marcello. Almagro: Universidad de Castilla-La Mancha-Festival de Almagro, 2007. 209-39.

Diccionario de personajes de Calderón. Eds. Javier Huerta y Héctor Urzáiz. Madrid: Pliegos, 2002. 
Dixon, Victor. The Life and the Works of Juan Pérez de Montalbán with special reference to his plays. Tesis doctoral. University of Cambridge, 1958.

Dixon, Victor. "Un discípulo de Lope de Vega". Revista sobre teatro áureo 7 (2013a): 263-78.

Dixon, Victor. "New (and Ancient) Lights on the Life of Juan Pérez de Montalbán”. Bulletin of Spanish Studies 90 (2013b): 509-34.

Eder, Maciej, Jan Rybicki y Mike Kestemont. "Stylometry with R: A Package for Computational Text Analysis". R Fournal 8.1 (2016): 107-21.

Eder, Maciej, Jan Rybicki y Mike Kestemont. “Stylo: A Package for Stylometric Analyses”. Computational Stylistic Group (2017). 20 de septiembre de 2018.

Empezar a ser amigos, comedia escrita en colaboración [Francisco de Rojas Zorrilla (II acto), Juan Pérez de Montalbán (III acto)]. Ed. Claudia Demattè. Dir. María Luisa Lobato. Alicante: Biblioteca Virtual Miguel de Cervantes, 2018. (Colección Digital PROTEO 7). 31 de julio de 2019. http://www.cervantesvirtual.com/obra/empezar-a-ser-amigos-940484/.

Escribir entre amigos: Agustín Moreto y el Teatro Barroco. Eds. María Luisa Lobato y Elena Martínez Carro. Madrid: Ayuntamiento de Madrid, 2018.

Fernández Guillermo, Leonor. "La silva: forma métrica clave en la obra dramática de Calderón”. Anuario calderoniano 1 (2008): 105-26.

Fradejas Rueda, José Manuel. "El análisis estilométrico aplicado a la literatura española: las novelas policíacas e históricas". Caracteres 5.2 (2016): 196-264.

García González, Almudena. "Una colaboración de éxito: Coello, Rojas y Vélez de Guevara". La comedia escrita en colaboración en el teatro del Siglo de Oro. Ed. Juan Matas Caballero. Valladolid: Universidad de Valladolid, 2017. 93-102.

González Cañal, Rafael. "Calderón y sus colaboradores". Calderón 2000: homenaje a Kurt Reichenberger en su 80 cumpleaños. Ed. Ignacio Arellano Ayuso. Vol. 1. Kassel: Reichenberger, 2002. 541-54.

González Cañal, Rafael. "Rojas Zorrilla y las comedias escritas en colaboración”. En torno al Teatro del Siglo de Oro. Fornadas XVI-XVII. Eds. O. Navarro y Antonio Serrano. Almería: Institución de Estudios Almerienses, Diputación de Almería, 2003. 29-43.

González Cañal, Rafael, ed. El universo dramático de Rojas Zorrilla. Valladolid: Ediciones de la Universidad de Valladolid, 2015.

González Cañal, Rafael. "La colaboración de Rojas con los hermanos Coello: El robo de las Sabinas". La comedia escrita en colaboración en el teatro del Siglo 
de Oro. Ed. Juan Matas Caballero. Valladolid: Universidad de Valladolid, 2017. 113-26.

Hilborn, Harry Warren. A Chronology of the Plays of Don Pedro Calderón de la Barca. Tesis doctoral. University of Toronto, 1935.

Hilborn, Harry Warren. "Calderón's silva”. PMLA 58.1 (1943): 122-48.

Kennedy, Ruth Lee. The Dramatic Art of Moreto. Philadelphia: George Banta, 1932.

La adúltera penitente, comedia escrita en colaboración Comedias de Agustín de Moreto. Obras escritas en colaboración [7uan de Matos Fragoso, Jerónimo de Cáncer y Agustín Moreto]. Ed. Fernando Rodríguez-Gallego. Dir. María Luisa Lobato. Alicante: Biblioteca Virtual Miguel de Cervantes, 2019. (Colección Digital PROTEO, 8). 31 de julio de 2019. http://www.cervantesvirtual.com/obra/empezar-a-ser-amigos-940484/.

Lágrimas panegíricas a la temprana muerte del (...) insigne fuan Pérez de Montalbán, publicadas por don Pedro Grande de Tena. Madrid: Imprenta del Reino, 1639.

Marín, Diego. "Función de la versificación en Calderón". Estudios sobre Calderón. Ed. Juan Aparicio Maydeu. Vol. 1. Madrid: Istmo, 2000. 351-60.

Mesonero Romanos, Ramón de, ed. Comedias escogidas de don Francisco de Rojas Zorrilla. BAE 54. Madrid: Atlas, 1952.

Parker, Jack H. "The Chronology of the Plays of Juan Pérez de Montalván". PMLA 67.2 (1952): 186-210.

Pedraza Jiménez, Felipe. Estudios sobre Rojas Zorrilla, Cuenca: Universidad de Castilla-La Mancha, 2007.

Pedraza Jiménez, Felipe. "El jardín de Falerina, de Rojas, Coello y Calderón y sus circunstancias". La comedia escrita en colaboración en el teatro del Siglo de Oro. Ed. Juan Matas Caballero. Valladolid: Ediciones Universidad de Valladolid, 2017. 217-28.

Pérez de Montalbán, Juan. Obra no dramática. Ed. Enrique Laplana Gil. Madrid: Castro, 1999.

Pérez de Montalbán, Juan, ed. Fama postuma a la vida y muerte del doctor frey Lope Félix de Vega Carpio y elogios panegíricos a la inmortalidad de su nombre. Ed. Enrico Di Pastena. Pisa: Edizioni ETS, 2001.

Pérez de Montalbán, Juan, Primer tomo de comedias. Vol. 1.1. Ed. Claudia Demattè. Kassel: Reichenberger, 2013.

Pérez de Montalbán, Juan. Primer tomo de comedias. Vol. 1.2. Ed. Claudia Demattè. Kassel: Reichenberger, 2014. 
Pérez de Montalbán, Juan. Comedias varias. Vol. 3.1. Ed. David Arbesú. Kassel: Reichenberger, 2016.

Pérez de Montalbán, Juan. Primer tomo de comedias. Vol. 1.3. Ed. Claudia Demattè. Kassel: Reichenberger, 2017.

Pérez de Montalbán, Juan. Segundo tomo de comedias. Vol. 2.1. Ed. Claudia Demattè. Kassel: Reichenberger, 2019.

Plata, Fernando. "La polémica en torno a La Perinola de Quevedo con un texto inédito". La Perinola 10 (2006): 245-55.

Quevedo, Francisco de. Obras festivas. Ed. Pablo Jauralde Pou. Madrid: Castalia, 1981.

Quiñones de Benavente, Luis. Entremeses completos. Vol. 1. Focoseria. Eds. Ignacio Arellano, Juan Manuel Escudero y Abraham Madroñal. Frankfurt am Main: Vervuert / Madrid: Iberoamericana, 2001.

Restori, Antonio. Piezas de títulos de comedias. Messina: Muglia, 1903.

Rojas Castro, Antonio. "Luis de Góngora y la fábula mitológica del Siglo de Oro: clasificación de textos y análisis léxico con método informáticos". Studia Aurea 11 (2017): 111-42.

Rojas Zorrilla, Francisco. Teatro. Ed. Raymond Mac Curdy. Madrid: Espasa Calpe, 1961.

Trambaioli, Marcella. "La fingida Arcadia de 1666. Autoría y escritura de consumo". Moretiana: adversa y próspera fortuna de Agustín Moreto. Eds. María Luisa Lobato y Juan Antonio Martínez Berbel. Frankfurt am Main: Vervuert / Madrid: Iberoamericana, 2008. 185-206.

Vega, Lope de (atr.). El sufrimiento premiado. Ed. Victor Dixon. London: Tamesis Books, 1967.

Vega García-Luengos, Germán. "Más vale maña que fuerza: los enredos albaneses de una comedia desconocida". Francisco de Rojas Zorrilla, poeta dramático. Eds. F. B. Pedraza Jiménez, R. González Cañal y E. E. Marcello. Ciudad Real: Universidad de Castilla-La Mancha, 2000. 55-88.

Vega García Luengos, Germán. "Sobre la autoría de El privilegio de las mujeres". "Non omnis moriar": estudios en memoria de fesús Sepúlveda. Eds. Álvaro Alonso y Jesús Ignacio Díez. Málaga: Universidad de Málaga, 2007. 317-22.

Vega García-Luengos, Germán. "Problemas de atribución y crítica textual en Rojas Zorrilla". El teatro del Siglo de Oro: edición e interpretación. Eds. Alberto Blecua, Ignacio Arellano y Guillermo Serés. Pamplona: Universidad de Navarra / Madrid: Iberoamericana / Frankfurt am Main: Vervuert, 2009. 480-83. 
Vega García-Luengos, Germán. "Uso y usufructos de Calderón en las comedias colaboradas". La comedia escrita en colaboración en el teatro del Siglo de Oro. Ed. Juan Matas Caballero. Valladolid: Ediciones Universidad de Valladolid, 2017. 181-202.

Volpe, Germana, ed. Pedro Calderón de la Barca, Juan Pérez de Montalbán, Francisco de Rojas Zorrilla. Comedia famosa El Monstruo de la Fortuna. La lavandera de Nápoles, Felipa de Catanea. Napoli: Il Torcoliere Editore, Università degli Studi di Napoli "L'Orientale", 2006.

Williamsen, Vern G. "La función estructural del verso en la comedia del Siglo de Oro". Actas del Quinto congreso de la Asociación Internacional de Hispanistas. Eds. Maxime Chevalier y otros. Bordeaux: Instituto de Estudios Ibéricos e Iberoamericanos, Universitè de Bordeaux, 1978. 883-91. 